\section{Curriculum Design for Upper- and Advanced-level GIS Classes: Are New Skills being Taught and Integrated?}

Gl_Forum 2016, Vol.1

Page: 324-335

Full Paper

Corresponding Author:

pkedron@ryerson.ca

DOI: 10.1553/giscience2016_01_s324

\author{
Peter Kedron', Amy Frazier2, Christopher Greene' and Danielle Mitchell' \\ 1 Ryerson University, Toronto, Canada \\ 2 Oklahoma State University, Stillwater, U.S.A
}

\begin{abstract}
Geographic Information System (GIS) skills are increasingly marketable across a wide range of industries, subject areas and specialized fields. As a result, GIS courses draw students from a plethora of disciplines beyond geography, including business, social sciences, agriculture, geology, natural resources and computer science. At advanced teaching levels, this disciplinary diversity generates questions about how complex GIS skills are being taught to students who do not necessarily have a background in geography or the spatial sciences. This study compares undergraduate and graduate course curricula to determine what topics, techniques and theory are being addressed and prioritized in GIS courses across pedagogical levels. We surveyed 1,698 courses being taught at 126 research universities in the United States. Our findings point towards a shift in pedagogy that favours technique- or application-centred lessons at advanced levels that require less background knowledge in geography than more theory-centred teaching methods. Our findings also suggest that a large number of graduate courses, even introductory courses ones, fail to address many fundamental GIS concepts and theories. Together, the results suggest a need for standards to ensure that students enrolled in GIS classes are properly trained to enter the workforce with appropriate skills.
\end{abstract}

\title{
Keywords:
}

GIS\&T curriculum design; course content analysis; GIScience; GIS\&T BoK

\section{Introduction}

The skills needed to engage with and operate Geographic Information Systems (GIS) are now not only marketable across a wide range of industries, subject areas and specialized fields, but are also becoming an essential requirement for a considerable suite of professionals (Montagu, 2001; Longley et al., 2015). As a result, GIS courses now frequently draw students from a range of disciplines extending beyond geography to include business, social sciences, agriculture, geology, natural resources and computer science, to name just a few. The attraction of GIS courses to a broad range of majors is particularly pronounced at 
the graduate and upper-undergraduate levels, where students are often looking to complement their major field of study with techniques to increase their marketability. While introductory GIS courses are taught across a range of disciplines (Morgan \& Fleury, 1993), upper-level undergraduate and graduate GIS classes are more commonly offered through geography departments, where instructors have historically placed a strong emphasis on the traditions of geography. In such contexts, GIS capabilities tend to be used as another tool to emphasize the more traditional theoretical and educational aspects of spatial analysis (Sui, 1995). Students looking simply to gain technical skills as a means of increasing their marketability are often unaware of the theoretical fundamentals that underlie spatial analyses and the geographic discipline. Moreover, application-oriented courses that ignore the conceptual dimensions of GIS and spatial analysis may not be preparing students sufficiently for solving real-world problems (Wikle \& Fagin, 2014).

Debates surrounding the content of GIS curricula have a long history. The rapid growth of GIS education throughout the 1980s and 1990s prompted a flurry of research focusing on the pedagogy surrounding GIS education and its link to the core teachings of geography (Sui, 1995; Walsh, 1992). Much of this discourse concerned arguments regarding whether a theoretical or a hands-on approach was the most appropriate method for teaching GIS; in other words, whether curricula should focus on learning about GIS or learning with GIS (Sui, 1995). In many cases, these arguments have diminished in recent decades through joint lecture-laboratory courses in which students spend part of the time in lectures learning the theoretical foundations and part of the time in the lab learning hands-on software applications. Nonetheless, findings suggest that the content of GIS courses remains largely ad hoc. For example, examining the North American context, Fagin and Wikle (2011) find that instructors at two-year colleges place different emphases on topics than those at fouryear univeristies.

Debate surrounding GIS teaching has shifted towards the content of GIS classes, and in particular the curriculum planning aspect. At the introductory level, early standards such as the National Center for Geospatial Information and Analysis (NCGIA) Core Curriculum (Goodchild \& Kemp, 1990; Kemp, 1996) and the Geographic Information Science and Technology Body of Knowledge (GIS\&T BoK) provided educators with a guide to ensure students taking GIS classes received basic foundational knowledge (DiBiase et al., 2006). Specifically, the GIS\&T BoK initiative arose from concern that undergraduate students were not being adequately prepared for workplace demands, particularly in view of the variety of student constituencies entering GIS courses (ibid.). However, in contrast to the increasing number and variety of GIS courses in recent years, curriculum planning for those courses has received relatively little attention in the literature (Wikle \& Fagin, 2014). Moreover, while many of the 'standards documents' (e.g., GIS\&T BoK) suggest a sequencing of course topics, they are largely silent on what skills should be taught at different pedagogical levels. At the same time, the skills that are taught have not necessarily evolved in step with technological advances over the past decade.

Recent developments in data sources and software platforms used to undertake GIS-related work have instigated renewed efforts to update the GIS\&T BoK. In addition to traditional sources, GIS data are increasingly derived from large, continuously-generated datasets made available through web-based platforms. The emergence of volunteered geographic 
information (Goodchild \& Li, 2012; Haklay, 2013), the geospatial web (Scharl \& Tochtermann, 2009), and GeoWikis (Guptill, 2007) add a new set of topics to the body of knowledge that is fundamental to understanding and analysing spatial data. For example, largely open source internet-accessible data that fail to match a random sampling scheme (e.g., volunteered geographic information) are bringing into question the appropriateness of traditional statistical techniques (Goodchild \& Li, 2012; Brown et al., 2014). Similarly, accessing and compiling such data through web-scraping approaches requires new methodological skills not included in current standards documents. Early efforts to track this constantly-changing knowledge set have attempted to leverage crowd-based platforms to continually update the body of knowledge, while offering potential guidance to those responsible for GIS course development. The efforts of Ahearn and Skupin are particularly notable for their development of an interactive GIS\&T BoK wiki (www.gistbok.org). However, there still remains a dearth of content-specific guidance at different pedagogical levels (e.g., undergraduate introductory/advanced, graduate introductory/advanced).

Collectively, changes in the audience, data environment, and GIS\&T BoK raise fundamental questions about the current shape of GIS teaching and curriculum development and what their future direction will be. With such diversity in both the contributing knowledge and professional opportunities, there is a temptation to emphasize the 'buttonology' aspects of GIS to the detriment of sound conceptual foundations and more complex forms of spatial analysis. As the power of GIS is recognized beyond geography, and as the data sources and software platforms become increasingly integrated with and reliant on the internet, it is important to revisit the theoretical and educational focus of GIS courses across pedagogical levels to ensure that the principles and training simultaneously match changing environments while providing theoretical foundations and complex spatial analytical skills.

In this paper we compare course curricula across several pedagogical levels (undergraduate introductory/advanced, graduate introductory/advanced) to determine what skills, techniques and theory are being addressed in GIS courses in different departments and universities. Specifically, we address two central concerns: (1) the degree to which courses taught at different pedagogical levels address the spatial body of knowledge while incorporating new, and more advanced, knowledge into their curriculum, and (2) to what degree the spatial skills being taught across all levels of GIS courses are being integrated into professional development through project-based approaches. Through this two-fold approach, we seek to address the following specific questions: What skills are being taught in upper-level GIS courses, and are these skills different from those taught in introductory courses? Do the content and skills being taught in upper-level and graduate courses advance beyond the basic GIS fundamentals set forth in the GIS\&T BoK? Is there significant repetition in the topical coverage of introductory and advanced courses?

To address these questions we developed a database of 1,698 GIS courses being taught at 126 research universities in the United States. Our findings point towards a shift in pedagogy (particularly at the graduate level) that favours technique- or application-centred lessons which require less background knowledge in geography than theory-centered lessons. Our findings also suggest that many graduate courses, even if they are introductory courses, do not address fundamental GIS concepts and theories. Together, the results suggest a need for 
better standards to ensure that students are properly trained to enter the current workforce with appropriate spatial skills and foundational GIS knowledge.

\section{Methods}

To assess the focus and content of current GIS curricula at undergraduate and graduate levels, we developed a database of course syllabi through an internet-based search of postsecondary institutional websites. Course syllabi provide a permanent record of what took place (or a contract of what will take place) within the classroom (Parkes \& Harris, 2012) and therefore provide a reliable record of the body of knowledge being taught. A syllabus typically includes a description of the objectives of the course, the required textbook or other reading materials, an overview of student evaluation, a schedule of topics, and sometimes relevant software used in the course (Wikle \& Fagin, 2014). For these reasons, course syllabi can be used to compare content, texts, evaluation methods, and topics being taught across courses, departments and universities.

Using the American Association of Geographers (AAG) 2014 Guide to Geography Programs in the Americas, we gathered information from 126 universities in the United States designated as 'Research Universities' by the Carnegie Classification System (Indiana University Center for Postsecondary Research, n.d.). While other types of universities (e.g., 4-year colleges, Masters granting, Tribal, etc.) offer GIS courses, we limited our analyses to those institutions that were most likely to offer both undergraduate and graduate courses at a variety of skill levels (i.e. introductory and advanced). After developing the list of universities, we began a web-based search of each institution to locate GIS courses. While a large number of courses employ GIS as a software platform, we limited our data collection to courses explicitly focused on GIS training. This eliminated from our sample courses such as 'Advanced Remote Sensing', which may use GIS software and techniques during the course of the semester, but are topically focused. Once an initial set of courses were identified from university course listings, a further search of departmental websites (e.g., geography, urban planning, environmental studies, etc.) was performed to ensure capture of further relevant courses. For this course list, we downloaded syllabi directly from course, departmental and instructor websites. Where available, syllabi were downloaded directly from the web. In most cases, syllabi were located on personal teaching or dedicated course websites. Available syllabi ranged in date from 2004 to 2015 , with $88 \%$ of collected syllabi tied to courses taught after 2010 , and $70 \%$ after 2013. In an effort to ensure measurement of recent teaching practices, we removed courses taught before 2010 from our sample.

Once syllabi had been located and downloaded, course information was entered into a database containing the categories outlined in Table 1. In addition to coding courses by university and department, we also coded information according to a four pedagogical levels that distinguished both undergraduate and graduate teaching at both introductory and advanced levels. Advanced courses were distinguished from introductory by the requirement of prior GIS coursework; they were typically taught in the third or fourth year of undergraduate study, or after the first semester of graduate study. To account for the range of terminology used to describe GIS concepts, we adopted the 17 thematic categories developed by Wikle and Fagin (2014), originally obtained from the GIS\&T BoK. 
Additionally, we recorded software and textbook information for each course. Finally, courses were categorized as to whether or not they adopted a project-based approach, which was defined as the inclusion of a student-developed project component worth at least $50 \%$ of a course grade and requiring the synthesis of multiple course topics.

Table 1: Data fields collected from course syllabi

\begin{tabular}{|l|l|}
\hline Fields & Details \\
\hline University Name & Listed \\
\hline Carnegie Classification & $\begin{array}{l}\text { Classification system for academic institutions in the United States in order to } \\
\text { identify groups of roughly comparable institutions. Classifications include: } \\
\text { Doctorate granting, Master's, Baccalaureate, Associates, Special focus and } \\
\text { Tribal. There can be sub-designations within each group. }\end{array}$ \\
\hline Course ID & Listed \\
\hline Course Name & Listed \\
\hline Department & Listed \\
\hline Pedagogical Level & $\begin{array}{l}\text { P1 - Undergraduate introductory; P2 - undergraduate advanced; P3 - graduate } \\
\text { introductory; P4 - graduate advanced }\end{array}$ \\
\hline Prerequisites & Listed \\
\hline Textbooks & Listed \\
\hline Course Topics & Selected from pre-defined list adapted from Wikle and Fagin (2014) \\
\hline Software & Listed \\
\hline Project Focus & $\begin{array}{l}\text { Yes/No: depending on whether course involved individual or group projects } \\
\text { worth at least 50\% of grade and requiring synthesis of course topics }\end{array}$ \\
\hline
\end{tabular}

\section{Results}

\section{Course Topics}

For the 126 research universities located across the United States, we successfully obtained and analysed syllabi for 2,131 courses. Of these, 1,698 met our criteria as GIS courses designed for multiple academic audiences and had syllabi of sufficient detail to allow further examination. We separated courses into undergraduate introductory $(\mathrm{n}=975)$, undergraduate advanced $(\mathrm{n}=313)$, graduate introductory $(\mathrm{n}=306)$, and graduate advanced $(n=77)$. The topical coverage of each course varied by pedagogical level and academic level (Table 2). 
Overall, undergraduate introductory courses covered an average of 7.2 different topic areas, while undergraduate advanced level courses covered an average of 7.6 topics. The increase in topics covered in undergraduate advanced courses may be due to review of introductory concepts in addition to presentation of new material. Graduate courses typically included a smaller number of topic areas, which may be due to course specialization and assumed prior coursework or training (discussed below). On average, graduate introductory courses addressed 5.4 topic areas, while graduate advanced courses covered 5.6. It is important to note that topic areas used in this study, as defined by the GIS\&T BoK, can comprise a number of sub-topics and GIS-related skills. For example, the basic analytical operations (vector) topic includes a range of buffer, overlay and map algebra techniques, among others.

Table 2: Percentage of courses teaching each topic

\begin{tabular}{|c|c|c|c|c|}
\hline \multirow[b]{2}{*}{ Course Topic } & \multicolumn{2}{|c|}{ Undergraduate } & \multicolumn{2}{|c|}{ Graduate } \\
\hline & Intro. & Adv. & Intro. & Adv. \\
\hline Basic Analytical Operations (Raster) & $42.6 \%$ & $47.6 \%$ & $34.6 \%$ & $31.2 \%$ \\
\hline Basic Analytical Operations (Vector) & $46.8 \%$ & $43.5 \%$ & $32.2 \%$ & $29.8 \%$ \\
\hline Cartography/Geovisualization Techniques & $46.2 \%$ & $39.3 \%$ & $33.1 \%$ & $26.0 \%$ \\
\hline Data Creation/Acquisition/Editing & $47.2 \%$ & $45.4 \%$ & $35.9 \%$ & $32.0 \%$ \\
\hline Database Management & $17.4 \%$ & $27.5 \%$ & $14.7 \%$ & $23.4 \%$ \\
\hline Georeferencing Systems & $22.1 \%$ & $17.3 \%$ & $9.1 \%$ & $16.9 \%$ \\
\hline Geostatistics/Spatial Statistics & $14.4 \%$ & $18.9 \%$ & $17.7 \%$ & $20.8 \%$ \\
\hline Metatdata standards and infrastructure & $2.1 \%$ & $4.5 \%$ & $1.3 \%$ & $3.9 \%$ \\
\hline Spatial Data models & $18.8 \%$ & $25.4 \%$ & $20.6 \%$ & $24.7 \%$ \\
\hline Network Analysis & $6.1 \%$ & $11.8 \%$ & $6.5 \%$ & $7.8 \%$ \\
\hline Attribute analysis & $7.6 \%$ & $8.3 \%$ & $8.2 \%$ & $7.8 \%$ \\
\hline Query Operations/Query Language & $8.0 \%$ & $7.1 \%$ & $5.6 \%$ & $6.5 \%$ \\
\hline Remote Sensing/Image Processing & $29.9 \%$ & $21.7 \%$ & $24.5 \%$ & $31.2 \%$ \\
\hline Programming/Scripting/ModelBuilder & $5.9 \%$ & $17.9 \%$ & $10.5 \%$ & $11.7 \%$ \\
\hline Project Management & $20.5 \%$ & $29.7 \%$ & $20.3 \%$ & $22.1 \%$ \\
\hline Special Topics & $7.7 \%$ & $9.6 \%$ & $11.8 \%$ & $11.7 \%$ \\
\hline Topology & $3.9 \%$ & $6.4 \%$ & $4.3 \%$ & $1.3 \%$ \\
\hline
\end{tabular}


At undergraduate level, the most common topics taught in both introductory and advanced courses were data creation, cartography, and vector- and raster-based basic analytical operations. Each of these topics was explicitly covered on over $40 \%$ of syllabi at both the introductory and advanced pedagogical levels. A second group of topics appearing on 20$30 \%$ of all undergraduate syllabi were a collection of topics linked to data management, such as spatial data models, georeferencing, and database management. Conversely metadata standards, geostatistics, attribute properties, topology, and network analysis were covered on less than $10 \%$ of all syllabi analysed. This progression of topical coverage in introductory and advanced undergraduate courses, from an emphasis on analytics in most courses to very little emphasis on theoretical topics such as topology, broadly suggests that many undergraduate GIS courses may not be training students in the fundamental spatial and GIS concepts. The[topics most commonly taught across courses appear to provide students with the skills needed to execute fundamental spatial analyses, but perhaps without a more nuanced understanding of GISystems or GIScience. Although uncommon across both introductory and advanced undergraduate courses, topics such as network and attribute analysis represented on less than $10 \%$ of introductory syllabi do appear to receive greater attention in advanced courses. Interestingly, newer and more advanced areas of knowledge, such as programming and scripting, are being incorporated into the undergraduate curriculum at both introductory (5.9\%) and advanced (17.9\%) levels.

Advanced undergraduate courses covered many of the same topics as introductory courses, but a smaller percentage of the advanced courses emphasized cartography and graphical representation techniques $(-1.8 \%)$ and georeferencing systems $(-4.8 \%)$, while those same courses increased the emphasis on scripting and model building $(+12.0 \%)$, database management $(+10.1 \%)$, and spatial data models $(+6.6 \%)$. A closer examination of syllabi revealed further heterogeneity in topic areas between introductory and advanced undergraduate syllabi. Although frequently covered on advanced undergraduate syllabi, common topics like cartography and graphical representation received less class time than in introductory undergraduate courses. These topics were often reviewed quickly during the first several weeks of a course, allowing more time for other, more advanced, topics during later weeks. In contrast, introductory syllabi tended to use more course time developing these fundamental topic areas. Project management skills also received greater emphasis in advanced undergraduate courses $(+9.2 \%)$, which corresponds with a high proportion of advanced courses (15.5\%) also having a project focus. Collectively, advanced undergraduate syllabi seem to suggest a design that teaches introductory topics early in a course, and then shifts to selected examination of other topic areas. Many of those topics receiving more or less emphasis in introductory courses are covered in more detail in advanced courses.

For the graduate courses, no single topic was covered on more than $36 \%$ of the syllabi indicating, potentially, more breadth and variation in graduate courses. Topics considered to be more advanced within the GIS\&T BoK, such as spatial statistics and remote sensing, were also covered on a greater proportion of graduate syllabi compared to undergraduate courses. The depth of topical coverage was often also greater in graduate courses. For example, undergraduate syllabi commonly contained graphical methods to describe statistical properties of data (e.g., histograms) but did not cover local measures of spatial autocorrelation, which were often included on graduate syllabi. Although programming was 
included on fewer graduate syllabi compared to undergraduate syllabi, graduate courses were more likely to include Python scripting and advanced modelling techniques when compared to undergraduate syllabi, which commonly introduced fundamental SQL query language.

Lastly, a project-based approach was uncommon across all course types included in this study. Of the course syllabi reviewed, only 138 met our definition for project-based, although these results may be due to our stringent definition of the term here. To be considered project-based, project components had to account for at least 50 percent of course grading and progressively incorporate and combine topical knowledge and skills developed throughout the course. At both graduate and undergraduate levels, a project approach was more common at advanced level, which aligns with expectations.

\section{Course Materials}

Of the 1,698 course syllabi reviewed, 652 included information on software used for course exercises. Esri's ArcGIS software package was by far the most commonly used software at all pedagogical levels. Over $65 \%$ of graduate and undergraduate courses were taught using ArcGIS. However, despite the predominance of ArcGIS in university classrooms, a small number of courses $(3.4 \%$ ) used open source GIS platforms such as QGIS and GRASS, primarily at the introductory course level. Similarly, open source programming languages like Python and $\mathrm{R}$ were also listed on $13.2 \%$ of syllabi, indicating that development of programming skills may be taking place in open environments.

Our analysis of textbook usage revealed 80 different textbooks being used across 476 courses. Introductory courses were the most likely to use a textbook $(n=273)$, followed by undergraduate advanced courses $(n=130)$, graduate introductory $(n=55)$, and graduate advanced $(n=15)$. These textbooks included many of the most popular, general GIS texts (see Table 2), as well as books focused on specific thematic GIS knowledge (e.g., Web GIS: Principles and Applications [Fu \& Sun, 2012]), spatial methods (Hierarchical Modeling and Analysis for Spatial Data [Banerjee et al., 2014]), programming (Think Python [Downey, 2012]), among many others. We can surmise from the list of texts that a wide variety of subject matter is finding its way into GIS courses. Of interesting note is the presence of what is a predominantly remote-sensing text (Remote Sensing of the Environment [Jensen, 2007]) on the list of the top five texts in GIS courses, even after remote-sensing focused courses were removed from analysis. This may be due to the large number of upper-level joint GIS and remote-sensing courses (e.g., 'GIS and Digital Image Processing).

Table 3: Top textbooks used in GIS courses, by pedagogical level

\begin{tabular}{|l|c|c|c|c|}
\hline & \multicolumn{2}{|l|}{ Undergraduate } & \multicolumn{2}{l|}{ Graduate } \\
\hline Textbook (Author*) & Intro. & Adv. & Intro. & Adv. \\
\hline $\begin{array}{l}\text { Geographic Information Systems and Science } \\
\text { (Longley et al., 2015) }\end{array}$ & 16 & 11 & 4 & 3 \\
\hline
\end{tabular}




\begin{tabular}{|l|c|c|c|c|}
\hline $\begin{array}{l}\text { GIS Fundamentals: A First Text on Geographic } \\
\text { Information Systems (Bolstad, 2012) }\end{array}$ & 34 & 11 & 1 & 2 \\
\hline $\begin{array}{l}\text { Remote Sensing of the Environment: An Earth } \\
\text { Resource Perspective (Jensen, 2007) }\end{array}$ & 15 & 13 & 4 & 1 \\
\hline $\begin{array}{l}\text { Introduction to Geographic Information Systems } \\
\text { (Chang, 2015) }\end{array}$ & 19 & 11 & 2 & 0 \\
\hline Mastering ArGGIS (Price, 2013) & 21 & 6 & 3 & 0 \\
\hline
\end{tabular}

*Citation provided for the most recent edition, although in many cases syllabi included earlier editions

Surprisingly, many advanced undergraduate courses, and even several advanced graduate courses, use introductory textbooks. This finding suggests that the various pedagogical levels of GIS courses may not actually be addressing different topics in the BoK or incorporating new knowledge into the curriculum. Textbooks are typically constructed with a 15-week semester in mind, but the re-use of these texts in advanced classes signals that some of the material may be too advanced to cover with introductory students, or that upper-level students have not fully grasped fundamental concepts. It may also signal a lack of appropriate course material for intermediate and advanced undergraduate courses.

\section{Discussion and Conclusions}

In this study, we performed a systematic evaluation of GIS courses being taught at research universities throughout the United States using course syllabi in order to assess (1) the degree to which courses, in particular advanced upper-level and graduate courses, are incorporating new and more advanced knowledge into their curriculum, and (2) to what degree the spatial skills being taught across all levels of GIS courses are being integrated through project-based approaches, as these are the skills that are most marketable across disciplines for professional development.

At undergraduate level, course topics appear skewed towards cartography/geographic representation, data acquisition/editing, and basic vector and raster analytical operations, which were found to be emphasized in both introductory and advanced coursework. While 'Cartography and Visualization' is indeed included as one of the components of the current GIS\&T BoK framework (2006), placing an emphasis on these skills at the expense of conceptual and theoretical foundations, data modelling and design aspects may be problematic. It is important for students to learn appropriate graphic representation techniques and principles of map design, but many would argue that analytical methods and general spatial conceptual thinking should not be sacrificed to these ends. Indeed, these types of broader skill sets are important during analysis, as they facilitate the identification and resolution of unexpected problems. Furthermore, it should be noted that courses explicitly focusing on cartography, map making and visualization were removed from analysis, so there may be some overlap, with these skills being taught both in GIS courses and elsewhere. 
Our findings show that, on average, undergraduate-level courses cover more topics during the course of a semester compared to graduate-level courses. While the exact reason for these differences cannot be discerned from syllabi, our analysis of the database showed that graduate-level classes are more likely to focus on a special topic (e.g., spatial statistics) than to provide advanced versions of broad GIS survey courses. The implication of specialization at graduate level is that graduate students from disciplines outside geography may take several GIS-related courses during their graduate studies without ever acquiring basic GIS knowledge, such as knowledge of georeferencing systems and spatial data models. Whether instructors assume that graduate students automatically possess this elementary knowledge by graduate school or these basic topics are deemed unimportant for learning the specialized material at hand, these findings suggest that graduate students who are 'doing GIS' in their research may lack appropriate conceptual foundations.

In terms of software, we were somewhat surprised by the overwhelming predominance of ArcGIS in the classroom and the lack of open source platforms and tools currently being used. One possible reason for the reliance on the ArcGIS package may be the demands of employers on their workforce (Esri remains the global industry leader) and ensuring that students are equipped with the software skills employers are seeking. Esri also offers discounted educational licences, which make it feasible to use in the classroom, and additionally there are numerous supplementary resources (e.g., the Getting to Know ArcGIS lab manual [Law \& Collins, 2015], and Mastering ArcGIS [Price, 2016]) which facilitate the instructor's adoption of ArcGIS in the classroom. Widespread adoption of open source platforms, such as QGIS, may be hindered by the lack of similar accompanying materials. However, as the BoK evolves to include emerging forms of web-based geospatial data (see Goodchild \& Li, 2012; Haklay, 2013; Scharl \& Tochtermann, 2009; Guptill, 2007), a move beyond ArcGIS may be warranted.

The use of foundational texts in upper-level undergraduate and graduate courses suggests that at least some courses are continuing to teach foundational concepts. However, the use of introductory texts (e.g., GIS Fundamentals: A First Text on Geographic Information Systems [Bolstad, 2012]) in graduate advanced courses suggests that appropriate texts that provide a mixture of foundational knowledge and upper-level or specialized material may not be available. We performed an additional web-based search for advanced GIS textbooks to determine whether this may in fact be the case, and it appears that such texts remain lacking. Most texts found were on special topics texts (e.g., Web GIS) and not general texts for advanced GIS skills. However, efforts such as the virtual revision of the GIS\&T BoK suggest the development of such materials may already be under way.

Lastly, a project-based approach appears largely absent from current upper-level and advanced GIS teaching practices. While laboratory exercises and small projects were common in many courses, far fewer required larger projects built on the recombination of multiple elements of the GIS\&T BoK. There may be many reasons for the lack of projects. First, given the time constraints of a typical GIS course and the observed need to review introductory material, little time may remain for training students in the critical skills needed to plan, execute and assess projects. However, the synthesis of knowledge and skills from the multiple areas of the GIS\&T BoK (Analytical Methods, Conceptual Foundations, Cartography and Visualization, Design Aspects, and Data Modeling) - or any standard 
document for that matter - is an important competency benchmark for upper-level and advanced students (particularly graduate students) of GIS.

There are several limitations of the current study that need to be mentioned. First, our analysis only examined institutions in the United States that are listed in the AAG Guide to Programs. Course topics and focuses, textbooks, software, and other aspects of curricula are likely to vary in institutions in other countries and global regions. Second, our analysis was limited to 'High' and 'Very High' research productivity universities to ensure a depth of courses at both the undergraduate and graduate levels, but these universities are also likely to have greater resources for purchasing software and hardware and may enforce different learning outcomes (e.g., stressing research output over conceptual understanding). Lastly, while syllabi provide a permanent record of what took place in the classroom (Parkes \& Harris, 2012), they do not necessarily provide the entire picture of knowledge gained by students throughout the course of a semester. For example, although we looked at whether there was a project focus in the class, we did not investigate whether specific project skills, such as hypothesis formation, study organization, or writing skills, were taught alongside technical GIS skills. These and other skills may be taught by an instructor but simply not noted on the syllabus since they do not directly relate to GIS topics.

\section{References}

Banerjee, S., Carlin, B. P., \& Gelfand, A. E. (2014). Hierarchical modeling and analysis for spatial data. CRC Press.

Bolstad, P. (2012) GIS Fundamentals: A First Text on Geographic Information Systems, 4th edition. Eider Press.

Brown, G., Kelly, M., \& Whitall, D. (2014). Which 'public'? Sampling effects in public participation GIS (PPGIS) and volunteered geographic information (VGI) systems for public lands management. Journal of Environmental Planning and Management, 57(2), 190-214.

Chang, K. T. (2015) Introduction to Geographic Information Systems (8th Edition). McGraw-Hill.

DiBiase, D., DeMers, M., Johnson, A. B., Kemp, K. K., Plewe, B. P \& Wentz, E. A., eds. (2006) The Geographic Information Science and Technology Body of Knowledge, Washington, DC: Association of American Geographers

Downey, A. (2012). Think Python. O'Reilly Media, Inc.

Fagin, T. D. \& Wikle, T. A. 2011 The Instructor Element of GIS Instruction at US Colleges and Universities. Transactions in GIS, 15(1):1-15.

Fu, P., \& Sun, J. 2010. Web GIS: principles and applications. Esri Press.

Goodchild, M. F. \& Kemp, K. K. (1990) NCGIA Core Curriculum in GIS. Santa Barbara, CA, National Center for Geographic Information and Analysis, University of California, Santa Barabara

Goodchild, M. F., \& Li, L. (2012). Assuring the quality of volunteered geographic information. Spatial statistics, 1, 110-120.

Guptill, S. C. (2007). GIScience, the NSDI, and GeoWikis. Cartography and Geographic Information Science, 34(2), 165-166.

Indiana University Center for Postsecondary Research (n.d.). The Carnegie Classification of Institutions of Higher Education, 2015 edition, Bloomington, IN: Author.

Jensen, J. (2007) Remote Sensing of the Environment: An Earth Resource Perspective, Prentice Hall, $608 \mathrm{p}$. 
Jensen, J. R. \& Jensen, R. R. (2013) Introductory Geographic Information Systems, Prentice Hall, 432p.

Kemp, K. K. (1996) The original NCGIA Core Curriculum in GIS. In Proceedings of the Second International Symposium on GIS in Higher Education (GISHE '96), Columbia, Maryland.

Law, M. \& Collins, A. (2015) Getting to Know ArcGIS (4th Edition). Esri Press.

Longley, P.A., Goodchild, M., Maguire, D.J., \& Rhind, D.W. 2015. Geographic Information Systems and Science, 4th Edition. Wiley, 496p.

Montagu, A. S. (2001) Repackaging the Revolution: Making GIS Instruction Relevant to Planners. Journal of Planning Education and Research, 21:184-195.

Morgan, J. M., \& Fleury, B. B. (1993). Academic GIS education: assessing the state of the art. Geographic Information Systems, 3(4).

Parkes, J. \& Harris, M. B. 2012. The purpose of a syllabus. College Teaching 50: 55-61.

Price, M. (2016) Mastering ArcGIS (7th Edition). McGraw-Hill.

Scharl, A., \& Tochtermann, K. (Eds.). (2009). The geospatial web: How geobrowsers, social software and the Web 2.0 are shaping the network society. Springer Science \& Business Media.

Sui, D. Z. (1995) A Pedagogic Framework to Link GIS to the Intellectual Core of Geography. Journal of Geography, 94:578-591.

Walsh, S. J. (1992). Spatial education and integrated hands-on training: Essential foundations of GIS instruction. Journal of Geography, 91(2), 54-61.

Wikle, T. A., \& Fagin, T. D. (2014). GIS Course Planning: A Comparison of Syllabi at US College and Universities. Transactions in GIS, 18(4), 574-585.

Wikle, T. A. \& Finchum, A. (2003) The emerging GIS degree landscape. Computers, Environment and Urban Systems, 27:107-122. 